\title{
RECONHECIMENTO COMO IGUALDADE E DIFERENÇA NA CONSTRUÇÃO DAS IDENTIDADES NEGRAS
}

\author{
RECOGNITION AS AN EQUALITY AND A DISTINCTION MATTER TO THE CONSTRUCTION OF \\ BLACK IDENTITIES
}

\author{
Gabriela Felden Scheuermann \\ Universidade Regional Integrada do Alto Uruguai e das Missões - URI \\ Mestra em Direitos Especiais \\ Professora do Curso de Direito na URI- Campus Cerro Largo \\ Cerro Largo / RS / Brasil \\ gabischeuermann.gf@gmail.com
}

\begin{abstract}
iD Noli Bernardo Hahn
Universidade Regional Integrada do Alto Uruguai e das Missões - URI Pós-doutor pela Faculdades EST. Doutor em Ciências da Religião, Ciências Sociais e Religião, pela UMESP. Graduado em Filosofia e Teologia. Possui formação em Direito. Professor Tempo Integral da URI, Campus de Santo Ângelo. Integra o Corpo Docente do Programa de Pós-Graduação Stricto Sensu - Mestrado e Doutorado em Direito. Lidera o Grupo de Pesquisa Novos Direitos em Sociedades Complexas, vinculado à Linha 1, Direito e Multiculturalismo, do PPG Mestrado e Doutorado em Direito da URI. Pesquisa temas relacionando Gênero, Direito, Cultura e Religião. Santo Ângelo / RS / Brasil nolihahn@san.uri.br
\end{abstract}

Resumo: Este artigo tem como tema a construção das identidades negras com base na teoria de Charles Taylor e dos conceitos de igualdade e diferença. A questão que guia a pesquisa é esta: como as ideologias racistas, difundidas por meio de falas e imagens depreciativas, atingem a construção das identidades negras? A tese que se argumenta é a de que a ausência de representatividade e a presença de estereótipos e marcadores sociais influenciam negativamente na construção das identidades negras. O objetivo consiste, portanto, em analisar o quanto as ideologias racistas influenciam na construção de identidades negras. Usa-se predominantemente a abordagem epistêmica analítica e o modo de raciocínio dedutivo, sendo que procedimentalmente a pesquisa é bibliográfica. Como perspectiva de superação do racismo, aponta-se a necessidade de abrir caminhos para que as identidades negras sejam reconhecidas e vistas como iguais e diferentes, ao invés de diferentes e desiguais.

Palavras-chave: reconhecimento; identidade negra; igualdade/diferença.

Abstract: This article has as its theme the construction of black identities based on the theory of Charles Taylor and the concepts of equality and difference. The question that guides the research is this: how do racist ideologies, spread through derogatory speeches and images, reach the construction of black identities? The thesis that is argued is that the absence of representativeness and the presence of stereotypes and social markers have a negative influence on the construction of black identities. The objective, therefore, is to analyze how much racist ideologies influence the construction of black identities. The epistemic analytical approach and the deductive reasoning method are predominantly used, and the research is procedurally bibliographic. As a perspective to overcome racism, the need to open paths for black identities to be recognized and seen as equal and different, rather than different and unequal.

Keywords: recognition; black identity; equality/distinction.

Para citar este artigo (ABNT NBR 6023:2018)

SCHEUERMANN, Gabriela Felden; HAHN, Noli Bernardo. Reconhecimento como igualdade e diferença na construção das identidades negras. Revista Thesis Juris - RTJ, São Paulo, v. 10, n. 1, p. 133-147, jan./jun. 2021. http://doi.org/10.5585/rtj.v10i1.17824. 


\section{Considerações iniciais}

Falar sobre racismo não é uma tarefa fácil, ainda mais em uma sociedade que acredita não ser racista, como a sociedade brasileira. Não é fácil, no Brasil, revelar o racismo, mas é necessário. A história precisa ser recontada, mas a partir dos verdadeiros protagonistas dela. $\mathrm{O}$ Brasil só se tornou Brasil a partir do trabalho escravo. A história da escravidão é uma história de luta, de resistência, de sobrevivência. Uma história de sangue e de suor. É necessário falar sobre racismo, pois os negros deram suas vidas pela vida do Brasil e, ao final, foram arremessados à margem da sociedade como restos humanos sem valor. A abolição não significou igualdade, significou uma nova luta em busca de dignidade e de sobrevivência.

Com o fim da escravidão, era preciso reinventar outra forma de dominação. A elite branca e cientistas da época usaram a raça como forma de justificar e manter os negros em posição de inferioridade. A ideia de inferioridade de negros se transformou em uma ideologia e foi difundida por toda sociedade. Com isso, imagens e falas depreciativas passaram a ser (e ainda são) veiculadas e introjetadas na sociedade, criando estereótipos que rebaixam e menosprezam a cor negra. Por exemplo, quando o serviço ou o trabalho foi mal feito, diz-se que foi serviço de preto; quando a situação não está boa, fala-se a coisa "tá" preta; chama-se mercado negro quando o mercado promove ações ilegais e ilícitas; quando se faz uma piada com elementos cruéis e grotescos, o humor é negro; na obra Espelhos, Eduardo Galeano descreve, como uma das nove formas de personificação do Diabo, o diabo negro, como a noite, como o pecado; o negro é descrito como inimigo da luz e da inocência.

É tão introjetado que às vezes nem se percebe o quão racistas todas essas frases são e o quão esses termos são pejorativos e diminutivos. O negro, introjeta-se e internaliza-se, como sinônimo de ruim, de feio. Em telenovelas, pessoas negras, na maioria das vezes, são empregados, são motoristas, são seguranças. Não só as falas, mas os papéis sociais e a mídia também passam a ideia e a imagem de inferioridade negra. Pode parecer normal ouvir/falar frases racistas ou ver que a empregada da novela é negra e que o patrão é branco. Mas não é. Mais da metade de toda população brasileira é composta por negros e eles são excluídos dos espaços de maior visibilidade.

À vista disso, o problema desta pesquisa consiste em saber se imagens e falas depreciativas interferem na construção das identidades negras, tendo em vista que as identidades são construídas a partir do olhar do outro. A ausência de representatividade negra, em espaços importantes da sociedade, somado ao fato de depreciação da cor negra podem ser fatores influenciadores na construção de identidades negras? 
Para tanto, recorrendo-se predominantemente à abordagem epistêmica analítica e ao raciocínio dedutivo, esta pesquisa divide-se em três partes. Inicialmente, aborda-se o tema da raça e do racismo enquanto instrumento de dominação, tendo em vista que o emprego do termo raça foi, por muito tempo, um meio de pré-determinar os lugares na sociedade, isto é, de criar hierarquias e estabelecer lugares e papéis sociais.

Em um segundo momento, estuda-se a construção da identidade com base na teoria de Charles Taylor, filósofo canadense que nos ajuda a entender o tema da identidade e do reconhecimento como igualdade e diferença. Por fim, adentra-se na temática da construção das identidades negras diante da influência de marcadores sociais na representação do negro.

Nesta introdução já se destaca a afirmação que falar sobre racismo não é uma tarefa fácil, mas é uma ação emancipadora e libertadora. Emancipa, especialmente, quem cria consciência histórica do racismo. Liberta tanto quem fala, quanto quem ouve, como todo aquele que se deixa envolver com esta temática e esta realidade angustiante e criminosa, ainda tão presente em nossos dias.

\section{Raça enquanto instrumento de dominação}

A escravidão foi muito mais do que um processo econômico; a escravidão "moldou condutas, definiu desigualdades sociais e raciais, forjou sentimentos, valores e etiquetas de mando e obediência” (ALBUQUERQUE, 2006, p. 68). Pode-se dizer que, a partir da escravidão, criaram-se lugares pré-estabelecidos na sociedade, determinando quais são as pessoas que mandam e quais as que obedecem. A forma utilizada para a continuação da dominação branca e de justificação das desigualdades foi a utilização dos conceitos raça $a^{l}$ e racismo $^{2}$.

O termo raça, ao longo do tempo, foi utilizado para hierarquizar culturas e pessoas e se tornou uma ferramenta de legitimação do racismo. No Brasil, as teorias raciais ganharam

\footnotetext{
${ }^{1}$ Questiona-se o porquê de usar a palavra raça ao invés de usar, simplesmente, a de etnia. Valendo-se das palavras de Munanga (2003), a palavra etnia significa "um conjunto de indivíduos que, histórica ou mitologicamente, têm um ancestral comum; têm uma língua em comum, uma mesma religião ou cosmovisão; uma mesma cultura e moram geograficamente num mesmo território". Há, inclusive, segundo Munanga, alguns pesquisadores que fogem da palavra raça e a substituem por etnia. Porém, segundo o autor, esta alteração não altera em nada a realidade do racismo, pois não destrói a relação hierarquizada entre culturas diferentes que é um dos componentes do racismo. Noutros dizeres, "o racismo hoje praticado nas sociedades contemporâneas não precisa mais do conceito raça ou da variante biológica, ele se reformula com base nos conceitos e etnia, diferença cultural ou identidade cultural, mas as vítimas de hoje são as mesmas de ontem e as raças de ontem são as etnias de hoje (2003, p. 12-13).

${ }^{2}$ De acordo com o Dicionário de Política de Norberto Bobbio, Nicola Matteucci e Gianfranco Pasquino, o racismo pode ser definido como “a não descrição da diversidade das raças ou dos grupos étnicos humanos, realizada pela antropologia física ou pela biologia, mas a referência do comportamento do indivíduo à raça a que pertence e, principalmente, o uso político de alguns resultados aparentemente científicos (, para levar à crença da superioridade de uma raça sobre as demais. Este uso visa justificar e consentir atitudes de discriminação e perseguição contra as raças que se consideram inferiores" (1998, p. 1305). Para Munanga (2003), o racismo seria teoricamente "uma ideologia essencialista que postula a divisão da humanidade em grandes grupos chamados raças contrastadas que têm características físicas hereditárias comuns, sendo estas últimas suportes das características psicológicas, morais, intelectuais e estéticas e se situam numa escala de valores desiguais". Desse modo, racismo é uma crença na existência das raças naturalmente hierarquizadas pela relação intrínseca entre o físico e o moral, o físico e o intelecto, o físico e o cultural (2003, p. 07).
} 
destaque e tornaram-se assunto do dia em meados do século $\mathrm{XIX}^{3}$, próximo ao fim da escravidão. De acordo com Amorim (2013, p. 67), com o treze de maio, as antigas hierarquias sociais construídas e naturalizadas não poderiam mais ter a mesma forma. A relação senhor/escravo "não poderia mais ser acionada para cristalizar a inferioridade da população negra no Brasil". Por isso, as teorias raciais do século XIX tiveram um papel importante para continuar a legitimar as hierarquias raciais/sociais no pós-abolição.

A raça foi utilizada para hierarquizar as relações de poder, ou seja, "raça e identidade racial foram estabelecidas como instrumento de classificação social básica da população" (QUIJANO, 2005, p. 117). Desse modo,

\begin{abstract}
na América, $\mathrm{a}$ ideia de raça foi uma maneira de outorgar legitimidade às relações de dominação impostas pela conquista. A posterior constituição da Europa como nova id-entidade depois da América e a expansão do colonialismo europeu ao resto do mundo conduziram à elaboração da perspectiva eurocêntrica do conhecimento e com ela à elaboração teórica da ideia de raça como naturalização dessas relações coloniais de dominação entre europeus e não-europeus (QUIJANO, 2005, p. 118, grifo nosso.) [sic]
\end{abstract}

Quijano (2005, p. 118) destaca que a raça, na América, foi uma maneira de outorgar legitimidade às relações de dominação impostas pela conquista e se tornou o mais eficaz e durável instrumento de dominação social universal. Os povos conquistados e dominados foram, portanto, postos em uma situação natural de inferioridade. Com efeito, as identidades foram associadas às hierarquias, lugares e papéis sociais correspondentes. Em decorrência, o racismo - relação de dominação baseada na ideia de superioridade racial - foi assumido pelos conquistadores como elemento fundacional da relação de dominação (QUIJANO, 2005).

No mesmo sentido, Catharine Walsh (2010, p. 98) afirma que "raza es una idea, un constructo ideológico mental moderno y instrumento de dominación social, iniciado hace más de 500 años y que se mantiene virtualmente intocado hasta el presente". À vista disso, raça é uma categoria classificatória que "exerce influência real no mundo, por meio da produção e reprodução de identidades coletivas e de hierarquias sociais politicamente poderosas" (SCHWARCZ, 2012, p. 34). Desse modo, raça, nos dias atuais, existe como "representação poderosa, como um marcador social de diferença [...] a construir hierarquias e delimitar discriminações" (SCHWARCZ, 2012, p. 33).

\footnotetext{
${ }^{3} \mathrm{O}$ pensamento do século XIX baseia-se na desigualdade essencial entre as raças, que advém de uma leitura evolucionista da espécie humana. Conhecido como racismo científico, sustava a ideia de uma hierarquia racial "onde o branco europeu estava no cimo e os extraeuropeus na base, sendo, por isso mesmo, incapazes de alcançar sozinhos os estágios civilizatórios mais elevados” (RISÉRIO, 2012, p. 44).
} 
Falar de raça e de racismo, no Brasil, foi e, ainda, é polêmico ${ }^{4}$, vez que não existem "regras fixas de descendência biológica aceitos de forma consensual" (SCHWARCZ, 2012, p. 32). No Brasil, o racismo não incide sobre a origem racial das pessoas, mas sobre a cor da pele. Diferentemente, por exemplo, do que ocorre nos Estados Unidos, onde vige a one drop rule, regra de uma gota só. Lá, não há mestiços. Ou se é branco ou se é negro. Na verdade, pode até ser de cor branca mas ser considerado negro, pois o que vale não é a cor, mas a origem/descendência.

Quem estabelece claramente esta distinção é Oracy Nogueira. Para ele, existe o preconceito de marca e o preconceito de origem. O preconceito de marca é aquele relacionado a uma atitude desfavorável, "culturalmente condicionada, em relação aos membros de uma população, aos quais se têm como estigmatizados, seja devido à aparência, seja devido a toda ou parte da ascendência étnica que se lhes atribui ou reconhece" (NOGUEIRA, 2007, p. 292). Mas, "quando basta a suposição de que um indivíduo descende de certo grupo étnico para que sofra as consequências do preconceito" tem-se o preconceito de marca (NOGUEIRA, 2007, p. 292).

Assim, a classificação branco e não-branco é variável no Brasil, devido ao grau de mestiçagem. Nos Estados Unidos, ao contrário, o branqueamento "não implica incorporação do mestiço ao grupo branco. Mesmo de cabelos loiros, pele alva, nariz afilado, olhos verdes, o mestiço continuará sendo um negro" (NOGUEIRA, 2007, p. 294). Percebe-se, portanto, o porquê da complexidade quando se fala em raça no Brasil.

Por isso, a palavra raça deve ser compreendida, na atualidade, como fruto de uma construção social, histórica e cultural. O conceito raça, tal como empregado hoje, nada tem de biológico, a "construção baseada em traços fisionômicos, de fenótipo ou de genótipo, é algo que não tem o menor respaldo científico" (GUIMARÃES, 2008, p. 65). É um conceito carregado de ideologia, pois, como todas as ideologias, ele esconde uma coisa não proclamada: a relação de poder e de dominação" (MUNANGA, 2003, p. 06). No contexto atual, refere-se a uma construção ideológica/cultural que "no tiene, literalmente, nada que ver con nada en la estructura biológica de la especie humana (QUIJANO, 2011, p. 03).

No mesmo sentido, o Supremo Tribunal Federal, no julgamento da ADPF $\mathrm{n}^{\circ} 186^{5}$, entendeu que:

\footnotetext{
${ }^{4}$ Para Clóvis Moura, o racismo é polêmico porque não é uma conclusão tirada dos dados da ciência, de acordo com pesquisas de laboratório que comprovem a superioridade de um grupo étnico sobre outro, mas uma ideologia deliberadamente montada para justificar a expansão dos grupos de nações dominadoras sobre aquelas áreas por eles dominadas ou a dominar. [...] O racismo tem um conteúdo de dominação, não apenas étnico, mas também ideológico e político.

${ }^{5}$ A Arguição de Descumprimento de Preceito Fundamental (ADPF) 186 refere-se ao julgamento, realizado pelo Supremo Tribunal Federal, sobre a constitucionalidade do programa de cotas raciais adotado pela Universidade de Brasília (UnB).
} 
Se a raça foi utilizada para construir hierarquias, deverá também ser utilizada para desconstruí-las. Trata-se de um processo de três diferentes fases: (i) a construção histórica de hierarquias convencionais que inferiorizaram o indivíduo quanto ao status econômico e de reconhecimento pela mera pertença a determinada raça [...]; (ii) a reestruturação dessas hierarquias com base em políticas afirmativas que considerem a raça, voltando-se agora à consolidação do princípio da dignidade; (iii) a descaracterização do critério raça como critério de inferiorização e o estabelecimento de políticas universalistas materiais apenas (STF, 2012, p. 66, grifo nosso).

Noutros dizeres, o conceito de raça não se trata de um dado biológico, mas de "construtos sociais, formas de identidade baseadas numa ideia biológica errônea, mas eficaz socialmente, para construir, manter e reproduzir diferenças e privilégios" (GUIMARÃES, 1999, p. 153). O conceito de raça, desse modo, trata de um conceito histórico-cultural, artificialmente construído, para justificar a discriminação e, até mesmo, a dominação de alguns sobre outros. Essa dominação, agregada à ideia de inferioridade negra, pode influenciar e refletir na construção e na representação das identidades, especialmente das identidades negras.

\section{Construção das identidades e o reconhecimento em Charles Taylor}

A identidade nunca é dada, é sempre construída, disse Dubar (1997, p. 104). Ela é construída pelo olhar do outro. Não é uma criatura do "mundo natural ou de um mundo transcendental, mas do mundo cultural e social [...] somos nós quem fabricamos" (SILVA, 2014, p. 76). Por isso, as relações entre as pessoas na sociedade (processos de socialização) contribuem e afetam na construção das identidades.

Neste trabalho, o estudo acerca da construção e da representação das identidades será delimitado à teoria do reconhecimento de Charles Taylor, pois, para ele, o sujeito "precisa da comunidade para se realizar, para encontrar uma pertença que se constitui pela relação de outros-importantes" (SANTOS; LUCAS, 2015, p. 104), ou seja, a identidade é um processo dependente das relações com outros, de modo que identidade é a articulação entre igualdade e diferença.

A teoria proposta por Taylor é de que os sujeitos precisam do reconhecimento intersubjetivo para se realizarem, vez que a identidade depende das relações dialógicas com os demais membros da sociedade. Para Taylor, há uma necessidade e até mesmo uma exigência de reconhecimento (operado pelo processo dialógico), sendo essa necessidade uma das "forças propulsoras dos movimentos políticos nacionalistas" e a exigência, os anseios das minorias (TAYLOR, 2014, p. 241).

Taylor distingue duas mudanças importantes para a preocupação da questão da identidade e do reconhecimento. A primeira delas é o que denominou de "colapso de hierarquias 
sociais", que costumavam ser a base da honra; honra ligada ao antigo regime e, desse modo, ligada às desigualdades e às questões de preferências. Para que alguns tenham honra é essencial que nem todos tenham (cf. Montesquieu). Contrária à noção de honra, emprega-se hoje a noção moderna de dignidade, utilizada com um sentido universalista e igualitário: “dignidade [inerente] a todos os seres humanos (TAYLOR, 1998, p. 47; TAYLOR, 2014, p. 242).

A segunda mudança recaiu na "importância e intensificação do reconhecimento e consistiu na nova interpretação da identidade individual" (SANTOS; LUCAS, 2015, p. 108), ou seja, o surgimento de uma identidade individualizada também teria corroborado à valorização da noção do reconhecimento. O ponto central da identidade individual, segundo Taylor, é a de ser verdadeiro consigo mesmo e para com a sua maneira própria. Com isso, a identidade passa ser vista como um ideal de autenticidade (TAYLOR, 1998). A identidade como um ideal de autenticidade está baseada em um sentido moral, um sentido intuitivo do que é bem e do que é mal, do que é certo e do que é errado (TAYLOR, 2014, p. 245).

A autenticidade se dá, portanto, por meio da recuperação de um contrato moral consigo mesmo, ou seja, se é autêntico quando se está em contato, de modo independente, com os próprios sentimentos. Assim, "para sermos com plenitude, não precisamos mais estar necessariamente em contato com alguma fonte transcendental, mas sim com o mais profundo de nós mesmos (SANTOS; LUCAS, 2015, p. 108). Floresce, a partir de então, a construção de um sujeito reflexivo, conhecedor de si mesmo, fundamental para o reconhecimento e para a formação da identidade. Esse novo sujeito não é um sujeito monológico, pois as "experiências sociais determinam a sua capacidade de reconhecimento como indivíduo e uma percepção de si mesmo", e a "consciência de si" somente existe em uma estrutura dialógica (LUCAS; SCHNEIDER, 2009, p. 48).

Desse modo, para compreender a relação entre identidade e reconhecimento, é preciso ressaltar um aspecto fundamental da condição humana: o caráter dialógico. De acordo com Taylor (1998, p. 52), “tornamo-nos verdadeiros agentes humanos, capazes de nos entender e definir nossas identidades, quando adquirimos linguagens humanas de expressão". Assim, a identidade é construída “em diálogo com as coisas que nossos outros significantes desejam ver em nós e, às vezes, em luta com elas [...] nossa identidade depende, de forma crucial, de nossas relações dialógicas com os demais" (SANTOS; LUCAS, 2015, p. 108-09).

Nesse viés, a nossa identidade se constrói por meio do outro, por meio do reconhecimento ou do não-reconhecimento do outro (reconhecimento errôneo) e é a partir desse reconhecimento (correto ou incorreto) que os sujeitos vão se constituir como seres humanos. A 
ideia central, desse modo, é a de que o homem necessita da comunidade para se realizar, uma vez que a identidade é formada pelo contato com o outro, pela "troca contínua que permite que o sujeito se defina e se estruture pela comparação e pela diferença, ou seja, na medida em que interage com os demais, com o outro-diferente, constitui-se enquanto sujeito" (SANTOS; LUCAS, 2015, p. 107).

No conceito dado por Taylor, identidade é a compreensão de quem somos através do outro. Por isso, alerta para o reconhecimento errôneo ou o não reconhecimento, que pode prejudicar os sujeitos, reduzindo-os a uma imagem distorcida de inferioridade ${ }^{6}$. Os indivíduos podem sofrer danos caso as "pessoas ou sociedades ao redor deles lhes devolverem um quadro de si mesmas redutor, desmerecedor ou desprezível” (TAYLOR, 2014, p. 241). Na medida em que a identidade depende do outro, ela pode ser construída negativamente, por meio da exclusão ou da marginalização desses sujeitos que são definidos como outros (WOODWARD, 2014, p. $50)$.

Noutros dizeres, a formação da identidade não implica uma produção individual, isolada; ao contrário, a identidade precisa ser "negociada por meio do diálogo, parte aberto, parte interno, com o outro" (TAYLOR, 2014, p. 248).

Nesse contexto,

A importância do reconhecimento é universalmente admitida, de uma forma ou de outra: no plano íntimo, estamos todos conscientes de como a identidade pode ser formada ou deformada no decurso da nossa relação com os outros-importantes; no plano social, temos uma política permanente de reconhecimento igualitário. Ambos os planos sofreram a influência do ideal de autenticidade, à medida que este foi amadurecendo, e o reconhecimento joga um papel essencial na cultura que surgiu à volta desse ideal (TAYLOR, 1998, p. 56).

À vista disso, o reconhecimento atua em dois planos: no íntimo e no social. No plano íntimo, a formação da identidade é compreendida como parte de um diálogo e luta com os outros-importantes. No plano social, as identidades são formadas pelo diálogo e contribuem ao desempenho de um papel crescente para a política do reconhecimento igualitário (TAYLOR, 2014; SANTOS; LUCAS, 2015). O foco principal de Taylor recai na esfera social, lugar em que o discurso do reconhecimento se traduz na política do reconhecimento igual que, historicamente, desenvolveu-se em dois níveis distintos: (a) política da dignidade igual e (b) política da diferença.

\footnotetext{
${ }^{6}$ No tocante à identidade, destaca-se as palavras de Zygmunt Bauman: a identificação é também um fator poderoso na estratificação, uma de suas dimensões mais divisivas e fortemente diferenciadoras. Em um dos polos da hierarquia global emergente estão aqueles que constituem e desarticulam as suas identidades mais ou menos à própria vontade [...] No outro polo se abarrotam aqueles que tiveram negado o acesso à escolha da identidade, que não têm direito de manifestar as suas preferências e que no final se veem oprimidos por identidades aplicadas e impostas por outros - identidades de que eles próprios se ressentem, mas não têm permissão de abandonar nem das quais conseguem se livrar. Identidades que estereotipam, humilham, desumanizam, estigmatizam (2005, p. 44).
} 
A política da dignidade igual está relacionada a uma das mudanças antes mencionadas: a mudança da honra para a dignidade, de modo que esta política estabelece uma igual dignidade entre todos, ou seja, uma igualdade de direitos e de privilégios. O que se quer evitar com esta política é que se formem cidadãos de primeira classe e de segunda classe e, por isso, é possível fazer relação desta política com a igualdade formal (igualdade de todos perante a lei). No exemplo dado por Taylor, aqueles que, em razão da pobreza, se veem impedidos de usufruir ao máximo seus direitos, têm sido relegados para uma segunda classe e, em decorrência disso, precisam de uma ação de compensação por meio da igualdade.

A política da diferença, em contrapartida, refere-se à segunda mudança, ou seja, à noção moderna de identidade. Taylor ressalta, e com razão, que esta política também possui uma base universalista: todas as pessoas devem ser reconhecidas pelas suas identidades únicas (TAYLOR, 1998, p. 58). A diferença entre as duas é que a política da diferença requer que a identidade única do indivíduo seja reconhecida, ou seja, ser reconhecido como diferente dos demais [grifou-se].

Ambas as políticas se conflitam entre si, uma vez que demandam um tratamento que, ao mesmo tempo, reconheça as particularidades e ignore as diferenças (SANTOS; LUCAS, 2015, p. 111). Mas, em uma sociedade tão diversificada como a do Brasil, é preciso encontrar meios que possibilitam uma coexistência harmônica: é preciso um reconhecimento que reconheça o valor igual das diferenças de cada um.

Mas aqui surge um problema central: para que isso dê certo, ou seja, para que o sujeito se construa com base no reconhecimento do outro, é preciso que as relações estejam pautadas pelo respeito mútuo e pela tolerância, pois, quando não há nem respeito nem tolerância, o reconhecimento pode oprimir e excluir indivíduos ou grupos. O problema é, justamente, quando não existe esta reciprocidade do reconhecimento, caso que ocorre com os negros: durante séculos foi projetada uma imagem depreciativa, fazendo com que eles próprios se sentissem inferiorizados e moldassem suas identidades a partir de um reconhecimento errôneo. É sobre a questão da identidade negra que o tópico a seguir trata.

\section{Identidade negra e o reconhecimento como igualdade e diferença}

Considerando a construção da identidade como um processo que se dá por meio do diálogo com outros-importantes, donde se espera um reconhecimento recíproco, é possível que esses outros-importantes não reconheçam, ou o fazem de forma equivocada, com determinados

sujeitos/grupos da sociedade. É o que ocorre com os negros, por exemplo. Durante anos, a sociedade brasileira criou padrões hierarquizantes, lugares pré-estabelecidos e identidades 
prontas e construídas (inventadas). Por muitos anos, fez-se isso por meio de teorias raciais que demonstravam a inferioridade do sujeito negro em relação ao branco.

Alguns exemplos podem ser citados. Autores como Arthur de Gobineu repudiavam o cruzamento racial, tendo em vista que a mistura produziria "híbridos degenerados" (RISÉRIO, 2012). Gobineau afirmava que o resultado da mistura é sempre um dano (SCHWARCZ, 1993) e defendia que os negros estavam sempre e em tudo situados abaixo de brancos e amarelos (SCHWARCZ, 1993; DAMATTA, 1986). Ao lado de Gobineu, destaca-se também Nina Rodrigues, que tentou demonstrar sua tese (por meio de casos clínicos) de degenerescência negra causada pela mistura racial. Em seus estudos, constatou que "o cruzamento de raças resultou num produto desiquilibrado e de frágil resistência física e moral" e observou “acúmulos notáveis de tara hereditária degenerativa" (RODRIGUES, 2008, p. 1155). Ou seja, atribuiu-se ao negro um caráter de inferioridade, tanto que, de uma mistura entre um negro e um branco, o resultado seria um mestiço degenerado por conter uma gota de sangue negro.

Outro autor que pode ser mencionado é Silvio Romero que, ao contrário de Gobineau e Rodrigues, não via a miscigenação como fracasso. Ele já parte da constatação de que o Brasil é uma mistura racial. "Todo brasileiro é um mestiço, quando não é no sangue, o é nas ideias (MUNANGA, 1999, p. 52); o Brasil é um povo mestiçado, pouco adianta discutir se isto é um bem ou um mal" (SCHWARCZ, 1993, p. 202). Entretanto, o ponto central da sua teoria estava em acreditar que em "nossas mesclas raciais, o branco predominaria graças à sua superioridade física e mental" (RISÉRIO, 2012, p. 48). Noutras palavras, a mestiçagem, ao invés de ser causa do fracasso, passou a ser a redenção do Brasil, uma vez que "haveria uma preponderância do 'elemento branco' na composição genética dos descendentes dos cruzamentos inter-raciais, gerando, assim, através da miscigenação, um tipo nacional, com o fenótipo branco europeu" (PEREIRA, 2010, p. 50).

Nesse pensamento, as esperanças de um futuro nacional eram recuperadas, vez que o povo brasileiro estava no caminho do branqueamento (RISERIO, 2012, p. 48). Ou seja, para Romero, a miscigenação era apenas uma fase transitória para tornar a nação brasileira branca. Por isso, alerta Schwarcz (1993) que, apesar dos elogios à mestiçagem, não se deve ver em Silvio Romero um defensor da igualdade, uma vez que foi um fiel seguidor do determinismo racial. O problema (mas solução na época) é que o processo de mestiçagem tem como consequência a "dissolução da diversidade racial e cultural e a homogeneização da sociedade brasileira, com predominância biológica e cultural branca e o desaparecimento dos elementos não-brancos" (PEREIRA, 2010, p. 51). 
Teorias como essas prevaleceram durante muito tempo na sociedade. Teorias que sempre tiveram como objetivo inferiorizar o ser negro ou exterminá-lo, fazendo prevalecer, no lugar, o ser branco. Como visto, o mecanismo utilizado para justificar a inferioridade negra era a raça. Hoje, sabe-se que o conceito raça, em seu sentido biológico, não existe. Ele é um construto social de classificação, mas que continua sendo utilizado como mecanismo de dominação.

Ao contrário das teorias raciais antes utilizadas, hoje, a sociedade brasileira - branca -, para manter-se no poder como a identidade "universal", "padrão", "normal", inferioriza os negros por meio de imagens e frases depreciativas (racismo ideológico), fazendo com que muitos não tenham forças para resistir, vez que, muitas vezes, os negros as introjetam e criam em si mesmos uma ideia de autodepreciação; essa autodepreciação, segundo Taylor (2014), vem a ser um dos mais fortes instrumentos de sua opressão. A falta de reconhecimento da identidade não demonstra apenas o esquecimento do respeito. Ela pode "infligir uma ferida cruel ao oprimir suas vítimas de um ódio de si paralisante" (MUNANGA, 2012, p. 06).

A identidade, enquanto um processo dinâmico, se constrói por meio do outro, pressupondo alteridade, tolerância e respeito. Ocorre que o racismo dificulta esse diálogo entre os diferentes grupos que compõem a sociedade brasileira, estabelecendo o "binarismo identitário, ou seja, uma identidade do que é 'ser negro' de um lado, contraposta ao que é 'ser branco', baseadas em estereótipos negativos para os primeiros e positivos para os últimos" (SOUZA, 2006, p. 106).

O negro recebe a marca do estigma, tendo sua cor de pele como principal elemento de estigmatização. Isso pode acarretar ao ódio com relação ao seu corpo e a sua condição, "enveredando-se em um processo de autodestruição" (SOUZA, 2006, p. 112). Para ilustrar e demonstrar o poder que uma imagem ou que frases depreciativas possuem sobre a construção das identidades negras, cita-se o teste da boneca. O teste da boneca é um vídeo feito nos Estados Unidos, pelo Dr. Kenneth Clark, com o objetivo de identificar o processo de assimilação dos sujeitos negros.

O teste consiste em apresentar para crianças negras uma boneca branca e uma boneca negra enquanto o entrevistador faz perguntas como: qual a mais bonita, a mais gentil, a mais feia e a mais má. As crianças negras sempre escolhem a boneca branca como sendo a boa e bonita e a negra como a má e feia. Após o entrevistador ter ouvido a criança negra dizer que a boneca negra é feia e má, pergunta: “qual boneca mais se parece com você?” A criança sente o choque ao perceber que também é negra e então se dá conta que deve ser feia e má apenas por ser negra. 
Na mesma linha, cita-se um exemplo utilizado pela Ministra Cármen Lúcia durante o julgamento da ADPF 186:

\author{
No início da década de 90, dei de presente a duas sobrinhas umas bonequinhas \\ artesanalmente feitas. As duas eram bonecas negras. Uma das meninas encantou-se \\ com a sua bonequinha, achou uma gracinha o presente. A outra, linda menina de pele \\ negra, rejeitou o presente, não aceitou a boneca. \\ E eu dizia: \\ - Como não, esta boneca é linda! \\ E ela: \\ - Não é não, é feia, parece comigo! \\ A família descobriu que, em algum lugar sem amor, a menina construía dentro de si \\ uma imagem negativa de si a partir de algo que nem sabíamos (2012, p. 133).
}

A marca de uma pessoa tem um espelho que é outro. Quando alguém é marcado com um sinal de inferioridade, especialmente na infância, os sentimentos que passam a crescer são sentimentos negativos, de opressão e de rejeição própria. Os exemplos acima demonstram isso: um racismo implantado e introjetado no subconsciente das crianças - por imagens, por frases que influenciam na construção de suas identidades.

Se a identidade é construída por meio do outro, é necessário desconstruir determinados (pré)conceitos construídos com o tempo e enraizados na sociedade. Por isso, precisa-se uma revalorização do ser negro e de uma percepção, também, do que significa ser branco. Às vezes é preciso de uma voz de incentivo exterior, de uma imagem positiva, para que as pessoas negras se enxerguem como iguais, não como inferiores.

\title{
Considerações finais
}

Não é possível falar em identidade sem falar de igualdade e diferença. Construímo-nos e moldamo-nos por meio desse duplo olhar: somos iguais e diferentes ao mesmo tempo. Ocorre que, em tempos sombrios e perversos como os de hoje, tenta-se ignorar as diferenças e, segundo Warat, ignorar que os outros são diferentes é aniquilá-los como seres com existência autônoma. A diferença não deve ser algo assustador, como algo que devemos esconder ou menosprezar. O diferente é o que faz ser quem somos. É a essência de cada ser humano.

Os negros devem ser vistos nessa visão dual. Suas diferenças foram, durante anos, usadas como motivo de hierarquização, de estratificação social. A diferença, ao invés de ser associada à igualdade, era associada à desigualdade. Diferentes e desiguais. Por isso, os negros foram excluídos da sociedade e dos espaços de maior visibilidade. A cor negra passou a ser sinônimo de ruim, de feio, de errado. Esses sinônimos transformaram-se em falas e em imagens 
que, por sua vez, passaram a ser enraizados na sociedade. E o modo como os negros são representados e vistos influencia na sua autoestima e na sua autoconfiança. Portanto, influencia na construção das identidades negras.

O modo como os negros são vistos e representados é assunto bastante profundo e complexo, pois questões relacionadas ao racismo estão arraigadas a valores histórico-culturais da sociedade. Por isso, com o intuito de minimizar o racismo e o preconceito, os aspectos culturais necessitam ser (re)vistos e explorados. O ser negro precisa ser revalorizado e a identidade negra precisa ser construída a partir de novos olhares e de novos conceitos.

Desse modo, a resposta do problema de pesquisa lançado inicialmente é de que a ausência de representatividade e a presença de estereótipos e marcadores sociais influenciam negativamente na construção das identidades negras. Por isso, é necessário abrir caminhos para que as identidades negras sejam reconhecidas e vistas como iguais e diferentes, ao invés de diferentes e desiguais. Mas, para que isso ocorra, é necessário que o sujeito branco se coloque também em análise, para compreender que seus privilégios - materiais e simbólicos perpetuam o racismo. Portanto, abre-se possibilidades para estudar, em outras pesquisas e de forma mais aprofundada, o papel da branquitude na construção das identidades negras como forma de repensar as relações raciais.

O diálogo entre culturas permite a formação de novos horizontes e predispõe o homem a olhar e a escutar os outros, alterando suas concepções sobre o mundo. Assim, além de repensar os lugares sociais de brancos e de negros, acredita-se que as ações afirmativas em universidades poderão abrir espaço para um diálogo intercultural, com processos de reconhecimentos recíprocos e que tragam a "potencialidade de produzir encontros de diferenças e de igualdades que tendem a se reconhecer ou se rejeitar" (SANTOS; LUCAS, 2015, p. 246). Esse choque (entre o igual e o diferente) é inevitável e necessário dentro de uma democracia.

\section{Referências}

ALBUQUERQUE, Wlamyra R. de; FRAGA FILHO, Walter. Uma história do negro no Brasil. Salvador: Centro de Estudos Afro-Orientais; Brasília: Fundação Cultural Palmares, 2006.

BOBBIO, Norberto; MATTEUCCI, Nicola; GIANFRANCO, Pasquino. Dicionário de Política. 11.ed., Brasília: Editora Universidade de Brasília, 1998. Disponível em: $<$ https://edisciplinas.usp.br/pluginfile.php/145096/mod_resource/content/1/BOBBIO.\%20Dici on\%C3\%A1rio\%20de\%20pol\%C3\%ADtica..pdf>. Acesso em: 15 jun. 2019.

DAMATTA, Roberto. O que faz do brasil, Brasil? São Paulo: Rocco, 1986. 
DOGLAS, César Lucas; SCHNEIDER, Bruna Dallepiane. Multiculturalismo: identidades em busca de reconhecimento. Direito em Debate, n. 31, jan-jun. 2009. Disponível em: https://www.revistas.unijui.edu.br/index.php/revistadireitoemdebate/article/viewFile/640/362. Acesso em: 20 jun. 2019.

GUIMARÃES, Antônio Sérgio Alfredo. Racismo e anti-racismo no Brasil. São Paulo: Editora 34, 1999.

GUIMARÃES, Antônio Sérgio Alfredo. Classes, raças e democracia. São Paulo: Fundação de Apoio a Universidade de São Paulo: Editora 34, 2002.

GUIMARÃES, Antônio Sérgio Alfredo. Raça, cor e outros conceitos analíticos. In: SANSONE, Lívio; PINHO, Osmundo Araújo (Orgs.). Raça: novas perspectivas antropológicas. 2. ed., Salvador: Associação Brasileira de Antropologia: EDUFBA, 2008. Disponível em: 〈http://209.177.156.169/libreria_cm/archivos/pdf_948.pdf>. Acesso em: 11 jun., 2019.

MUNANGA, Kabengele. Rediscutindo a mestiçagem no Brasil: identidade nacional versus identidade negra. Petrópolis: Vozes, 1999.

MUNANGA, Kabengele. Política de Ação Afirmativa em benefício da população negra no Brasil: um ponto de vista em defesa das cotas. In: Silva, P. B. G., Silvério, V.R. (orgs.).

Educação e Ações Afirmativas: entre a injustiça simbólica e a injustiça econômica. Brasília: INEP/MEC, 2002.

MUNANGA, Kabengele. Uma abordagem conceitual das noções de raça, racismo, identidade e etnia. Palestra proferida no $3^{\circ}$ Seminário Nacional Relações e Educação PENESB-RJ, 2003. Disponível em: <https://www.geledes.org.br/wpcontent/uploads/2014/04/Uma-abordagem-conceitual-das-nocoes-de-raca-racismo-dentidadee-etnia.pdf>. Acesso em: 09 abr. 2020.

NOGUEIRA, Oracy. Preconceito racial de marca e preconceito racial de origem: sugestões de um quadro de referência para a interpretação do material sobre relações raciais no Brasil. Tempo Social, revista de sociologia da USP, v. 19, n.1. Disponível em: https://www.revistas.usp.br/ts/article/download/12545/14322. Acesso em: 09 abr. 2020.

PEREIRA, Amilcar. O mundo negro: a constituição do movimento negro contemporâneo no Brasil (1970-1995). Tese do Programa de Pós-Graduação em História da Universidade Federal Fluminense. Rio de Janeiro: 2010. Disponível em: <http://www.historia.uff.br/stricto/td/1254.pdf>. Acesso em: 10 abr. 2020.

QUIJANO, Aníbal. Colonialidade do poder, eurocentrismo e América Latina. In: LANDER, Edgardo (Org.). A colonialidade do saber: eurocentrismo e ciências sociais. Perspectivas latino-americanas. Buenos Aires: Colección Sur Sur, CLASCO, 2005. Disponível em: <http://www.antropologias.org/rpc/files/downloads/2010/08/Edgardo-Lander-org-AColonialidade-do-Saber-eurocentrismo-e-ci\%C3\%AAncias-sociais-perspectivaslatinoamericanas-LIVRO.pdf>. Acesso em: 09 abr. 2020.

RISÉRIO, Antônio. A utopia brasileira e os movimentos negros. 2. ed. São Paulo: Editora 34, 2012. 
RODRIGUES, Nina. Méstissage, dégénérescence et crime. Hist. Cienc. Saúde-Manguinhos, Rio de Janeiro, v.15, n.4. Dezembro, 2008. Disponível em:

<http://www.scielo.br/scielo.php?script=sci_arttext\&pid=S0104-

59702008000400013\&lng=en\&nrm=iso>. Acesso em 16 jun. 2020.

SANTOS, André Leonardo Copetti; LUCAS Doglas Cesar. A (in)diferença no Direito. Porto Alegre: Livraria do Advogado, 2015.

SCHWARCZ, Lilia Moritz. Nem preto nem branco, muito pelo contrário: cor e raça na sociabilidade brasileira. São Paulo: Claro Enigma, 2012.

SCHWARCZ. Lilia Moritz. O espetáculo das raças: cientistas, instituições e questão racial no Brasil - 1870-1930. São Paulo: Companhia das Letras, 1993.

SCHWARCZ, Lilia Moritz; STARLING, Heloísa Murgel. Brasil: Uma biografia. São Paulo: Companhia de Letras, 2015.

SOUZA, Jesse. A invisibilidade da desigualdade brasileira. Belo Horizonte: Editora UFMG, 2006.

TAYLOR, Charles. Multiculturalismo. Lisboa: Instituto Piaget, 1998.

TAYLOR, Charles. Argumentos Filosóficos. Tradução de Adail Ubirajara Sobral. 2.ed. São Paulo: Loyola, 2014.

WALSH, Catherine. Raza, mestizaje y poder: horizontes coloniales pasados y presentes. CRÍTICA Y EMANCIPACIÓN, jun., 2010. Disponível em:

<http://biblioteca.clacso.edu.ar/ojs/index.php/critica/article/view/169>. Acesso em: 5 abr. 2020.

WOODWARD, Kathryn. Identidade e diferença: uma introdução teórica e conceitual. In: SILVA, Tomaz Tadeu da (org.); HALL, Stuart; WOODWARD, Kathryn. Identidade e diferença: a perspectiva dos estudos culturais. 15.ed. Petrópolis: Vozes, 2014. 